University for Business and Technology in Kosovo

UBT Knowledge Center

Nov 2nd, 9:00 AM - 9:10 AM

\title{
Family Friendly Policies in Organizations and Their Effects on Work-Life Balance, Work Alienation and Life Satisfaction
}

Pelin Kanten

Mehmet Akif Ersoy University, pelinkanten@mehmetakif.edu.tr

Follow this and additional works at: https://knowledgecenter.ubt-uni.net/conference

Part of the Business Commons

\section{Recommended Citation}

Kanten, Pelin, "Family Friendly Policies in Organizations and Their Effects on Work-Life Balance, Work Alienation and Life Satisfaction" (2013). UBT International Conference. 33.

https://knowledgecenter.ubt-uni.net/conference/2013/all-events/33

This Event is brought to you for free and open access by the Publication and Journals at UBT Knowledge Center. It has been accepted for inclusion in UBT International Conference by an authorized administrator of UBT Knowledge Center. For more information, please contact knowledge.center@ubt-uni.net. 


\title{
Family Friendly Policies in Organizations and Their Effects on Work-Life Balance, Work Alienation and Life Satisfaction
}

\author{
Pelin Kanten ${ }^{1}$ \\ ${ }^{1}$ Mehmet Akif Ersoy University, School of Tourism and Hotel Management, \\ Burdur, Turkey \\ pelinkanten@mehmetakif.edu.tr
}

\begin{abstract}
This study aims to research the effect of family-friendly policies on work-life balance, work alienation, and life satisfaction. In the literature studies suggest that, family-friendly policies are evaluated within the scope of human resource management practices; they are associated with positive individual and organizational outcomes. Accordingly, this study deals with work-life balance, work alienation and life satisfaction variables which are expected to be affected by family-friendly policies. In order to examine the effect of family-friendly policies on these variables, 208 people employed in three different marble companies in Turkey are included in the research. Based on the findings, there are significant correlations between family-friendly policies and work-life balance, work alienation, and life satisfaction. Also, family-friendly policies affect worklife balance and life satisfaction negatively, whereas these policies affect work alienation positively.
\end{abstract}

Keywords: Family-friendly policies, work-life balance, work alienation, life satisfaction

\section{Introduction}

In recent years changing societal demographics, technological developments, increasing globalization, and international business competitiveness have contributed to a blurring of boundaries between job and family domains. These changes and concomitant shifts in job demands have bring out profound changes in family structures. There has been an increase in the number of dual-career couples, single parent families, and workers with eldercare responsibility. However, dual-earner family has increasingly substituted for the more traditional single-earner family and women's role are increasing in the labor force. With these shifts, a demand for a better balance between work and home life has greatly increased in the workplace (Brough, O'Driscoll and Kalliath, 2005: 223; Breaugh and Frye, 2008: 345). In response to these changes, many organizations have implemented programs or policies designed to help accommodate the needs of today's diverse workforce. These policies are commonly referred to as "family-friendly policies" and include some benefits for employees (Allen, 2001: 414). Family-friendly policies are generally considered as working arrangements which make it easier for individuals to manage their work and family lives (Haslett, Smith and Curry, 2008: 22). Family-friendly policies are broadly defined as a group of complementary benefits and programs designed to support employees who are faced with balancing the conflicting demands of work life, family and personal time in today's complex environment (Lee and Hong, 2011: 870). These policies encompass some benefits, such as flexible working arrangements (e.g. part-time, job share, term-time contracts, flextime, uncompressed working week, reduced hours and homeworking), leave arrangements (e.g. maternity, paternity, parental and bereavement or compassionate leave) and workplace facilities (e.g. crèches, nurseries, subsidized childcare and counselling/stress management provision etc. (Callan, 2007: 64; Baxter and Chesters, 2011: 141). Family-friendly policies have been a focus of increased organizational research for the last two decades both researchers and practitioners. Family-friendly policies have gain an importance in organizations because these programs portray what an organization stands for in terms of helping employees achieve a viable balance between work and life. There are several reasons why family-friendly programs are particularly important in contemporary organizations. Due to its importance, previous researches has drawn attention the role of these policies. Family-friendly policies as mechanisms to reduce employee absenteeism, stress, turnover, work alienation, conversely enhancing quality of work life, employee commitment, job satisfaction, and productivity (Allen, 2001: 
415; Poelmans, Chinchilla and Cardona, 2003: 129; Wang and Walumbwa, 2007: 397; Chou and Cheung, 2013: 4). Moreover, family-friendly culture improves wellbeing and morale's of employees and provides an integration family and work life in today's environment. In other words, family-friendly culture effect employee's work-life balance. Accordingly, it spreads of satisfaction and stimulation at work and satisfaction at home thus it facilities generally life satisfaction in time (Carlson, Kacmar and Williams, 2000: 245; Haslett, Smith and Curry, 2008: 25). In this context, it is possible to express that work-life balance, work alienation and life satisfaction consequences of family-friendly policies. In literature, there are some researches that show the consequences of family-friendly policies. For instance, most studies focus on the relationship of family-friendly policies with some of the variables such as job satisfaction, organizational commitment, turnover intention, absenteeism, work life balance, work life conflicts and general satis faction etc. However, there are not any research existing literature investigating the impact of family-friendly policies on work life balance, work alienation and life satisfaction together. Due to limited studies on the effects of these family-friendly policies on these variables, this study attempts to add contribution to the literature. In this context, the purpose of this study is to investigate the family-friendly policies on work life balance, work alienation and life satis faction of employees.

\section{Literature Review}

Family-friendly policies have emerged as a new and important issue in human resource management due to dramatic workforce change, economic and technological developments and competitive environment which in many cases leads to escalating demands on individual time and energy. In consequence of these societal and business -related changes, substantial increas es have place in levels of conflict or interference between the demands of work and family responsibilities (Brough, O'Driscoll and Kalliath, 2005: 224; Moon and Roh, 2010: 117). Therefore, prevention of work-family conflict is becoming an increasingly pressing problem for modern organizations in 21th century. For that reason, organizations have started to adopt family-friendly workplace policies make it possible for decrease employee's work-family conflict, provide more easily balance family and work, and to fulfill both their family and work obligations. By this way, family-friendly policies become an important issue in organizations, because it leads to create a committed workforce and facilitate retention of valuable professionals, employees and managers. (Poelmans, Chinchilla and Cardona, 2003: 129; Ciric, 2013: 11). In this context, family-friendly policies represent the antecedents of work-life balance, work alienation and life satisfaction. Because employees shape their views, work roles, attitudes and behaviors according to these policies.

Generally work-life balance defined as the extent to which individuals are equally engaged in and equally satis fied with their work and family roles. Work-life balance is a global assessment that work resources meet family demands, and family resources meet work demands thus it is expected that positive and negative consequences both employees and organizations. In literature, work life balance have been associated with employee commitment, job satisfaction, organizational citizenship, greater turnover intention and greater sickness absence. However work life balance leads to employees less effectively at work thus it leads to work alienation (Grzywacz and Carlson, 2007: 456-457; Tummers and Dulk, 2012: 3). Work alienation represents a generalized, indifferent outlook toward work that indicates an absence of enthusiasm, engagement and involvement. Work alienation aspect of the tendency to involve oneself in whatever one is doing or encounters in turn, is associated with such as optimism, self-esteem, depression, dissatisfaction with life (Hirschfield, Feild and Bedeian, 2000: 1880). Life satisfaction incorporates all the aspects of one's life in which he or she involved as in for their daily routine activities. When there is no conflict between both the work and non-work domain, employees satisfied with their life (Nawab and Iqbal, 2013: 104). Concordantly, it can be said that life satisfaction, work alienation and work life balance of employees expected an affect from some organizational variables such as workplace conditions, organizational culture, policies, procedures and etc. Family-friendly policies as seen as one of the important variable that is possible to affect them. Therefore, in this study, primarily it will be explained concepts of family-friendly policies, work life 
balance, work alienation and life satisfaction. Subsequently, it will be discussed the relationships between these concepts.

\subsection{Family-Friendly Policies}

Family-friendly policies refer to organizational programs that help organizational members evenly carry out responsibilities and missions in both work and family life (Moon and Roh, 2010: 117). Familyfriendly policies are defined as an institutionalized structural and procedural arrangements, as well as formal and informal practices aimed to design, create and maintain family-friendly work environments that allow individuals to balance their work and family duties (Zahavy and Somec, 2008: 273). From a broad perspective, family-friendly policies as arrangements designed to support employees faced with balancing the competing demands of work and family life, as well as work and other caring or community roles for all employees (Daves, 2004: 12). Although, these policies are generally designed to help accommodate the needs of today's diverse workforce, reflect different meaning for organization and employees. For the organization, family-friendly policies seen as a tool for maintaining competitive advantage, raising morale, and attracting and retaining a dedicated workforce within today's turbulent work environment. For the employees, these policies means as a facilitator to alleviate the difficulty inherent in coordinating and managing multiple life roles so employees see family friendly policies as resources that can be used in solving problems and resolving challenging situations, so as to balance the pressures from work and family (Allen, 2001: 414-415; Amah, 2010: 36). In this regard, it is understandable that family-friendly policies provide creating positive work environment which can be affect positively employees' attitudes and behaviors to their work roles and organizations. In conjunction with, it is possible to express that family-friendly policies exerting a direct positive influence on an organizational outputs.

Prior literature suggests that family-friendly policies are associated with numerous positive outcomes. Many researchers have examined the relationships between family friendly policies and several important positive work-related attitudes and behaviors such as organizational commitment, motivation, job satisfaction, life satisfaction, work-life balance, productivity and reduced work-family conflict, absenteeism, turnover intention, withdrawal behavior, stress etc. (Poelmans, Chinchilla and Cardona, 2003: 129; Wang and Walumbwa, 2007: 398; Ahmad and Omar, 2008: 16; Wang, Lawler and Shi, 2011: 494; Lee and Hong, 2011: 871; Kim and Wiggins, 2011: 729; Vuksan, Williams and Crooks, 2012: 5; Chou and Cheung, 2013: 3875). Based on these positive outputs, scholars have asserted that organizations need to focus on what contributes to a supportive culture and how to create a family friendly environment for their employees (Wang and Walumbwa, 2007: 398). Because family-friendly policies play a crucial role inducing employees discretionary effort in performing their work, helping them to be more productive, facilitate qualified employees attract and retained thus it effects to improve organizations' competitiveness (Bagilhole, 2006: 327). Accordingly, organizations attach great importance designing family-friendly policies which include several different types and procedures. For instance, some organizations focus on policies such as leave for maternity and paternity, sickness, emergencies and compassionate reasons, career breaks, extended leave, flexi-time, part-time work, jobsharing, compressed work week, teleworking etc. whereas others are emphas is that child-care and eldercare supports, work-family stress management, health promotions in addition to all these. These differences depends on several factors such as the size of the organization, the percentage of female employees, the proportions of low-skilled and high-skilled employees, the number of employees aged under 45, the sector and the tightness of the labor market (Remery, Doorne-Huiskes and Schippers, 2003: 466; Ahmad and Omar, 2008:16).

Family-friendly policies have been classified based on different views in the literature. At times, Poelmans et al., (2003) and Mulvaney (2011) researches family-friendly policies have been conceptualized into four distinct categories like dependent care supports (i.e., childcare, eldercare, school and holiday programs), flexible work arrangements (i.e., job sharing, flextime, compressed workweek, telecommuting, etc.), leaves and time off (i.e., family and medical leave, personal leave of absence, sabbatical) and work-family stress management (i.e., employee assistance programs, health promotion, work-family resource center, support groups, courses on life balancing, etc. Schwartz (1994), Remery et al, (2003) and Haslet et al., (2008) researches these policies categorized narrower which include three separate domains such as flexible work arrangements, leave arrangements and 
dependent care benefits. Consequently, in this study these policies will be examined in accordance classification of three dimension. With reference to this classification, there are three specific types of family-friendly policies. (Schwartz, 1994: 9-10; Poelmans, Chinchilla and Cardona, 2003: 133; Haslett, Smith and Curry, 2008: 22-24; Mulvaney, 2011: 60-61; Lee and Hong, 2011: 873):

- Flexible work arrangements; these are policies designed to give workers greater flexibility in scheduling hours, while not decreasing average hours per week. These are include flextime, telecommuting, compressed work weeks, part-time work, extended lunch breaks and job sharing. Flexible work schedules require employees to be on the job during core time, but allow for variations in start and stop times so these policies aim to help employees balance their work and family responsibilities

- Leave arrangements; these policies provide employees with time off to care for dependents. These are include leave for vacation, illness, parental leave, leave to care for an ill child or family member, to leave for pregnancy and maternity leave, emergency leave, long-term care leave and long-term career interruption etc. Leave arrangements provide employees satisfaction with their work and family life.

- Dependent care benefits; these policies are designed to provide social support to employees in the workplace. These include child care resource and referral, elder care resource and referral, on-site or near-site child care, vouchers for child care, child care centers, long-term care insurance, and health promotion, provide non-repayable aids. Dependent care benefits are closely linked to an organization's work-family culture and these policies facilitate balance between work and family responsibilities.

\subsection{Work Alienation}

Work alienation refers that employees may not be able to fulfill their social needs and they have a form of gap between perceptions of an objective work situation and their certain interests such as values, ideals, and desires. Work alienation cognitively separates an employee from work and the workplace and manifests itself in the form of decreased job involvement and a lack of organizational identification (Sulu, Ceylan and Kaynak, 2010: 29). This concept represents a generalized, unenthusiastic outlook toward the world of work that indicates a low level of engagement in the work role and portrays a low level of positive affect toward to their work (Hirschfeld and Field, 2000: 790). However, work alienation view as a "situational emergent" rather than a trait or personality feature and emerge due to the working conditions. Conditions in the workplace can contribute to decrease alienation. For example, working conditions such as job characteristics, organizational culture, structure, organizational justice, trust, policies, procedures, management styles are important and probable contributors to the observed level of alienation (Banai, Reisel and Probst, 2004: 377; Di Pietro and Pizam, 2007: 23). Accordingly, it can be interpreted that organizations' characteristics and organizational factors are believed to affect work alienation of employees. Because conditions in an organization are expected to shape employees' perception primarily, then exerting a direct influence on employee attitudes to their work in times. Work alienation evaluated as a strong personal involvement with one's work and if an individual feels disconnected or alienated, this might lead to lower levels of work motivation or self-management and ultimately decrease his or her work success so organizational performance should affected from this result. In other words, work alienation can be detrimental for individuals and organizations because it has negative consequences forboth individuals and organization. In literature, work alienation has been found to be negatively related to work attitudes including organizational commitment, job satisfaction, career satisfaction, organizational identification and organizational citizenship behavior. However, work alienation has positive relationships with tardiness, disengagement, frustration or aggression, burnout, workplace cynicism, apathy, psychosis and withdrawal (Nair and Vohra, 2012: 26-39; Chiaburu et al., 2013: 5). Due to these negative consequences, organizations must trying to understand what causes alienation and how these consequences can be prevented before they occur. As to achieve organizational effectiveness and competitive advantage, organizations need to provide positive working conditions for acquire committed workforce. 


\subsection{Work-Life Balance}

Work-life balance is defined according to variety of views and widespread in academic researches. Generally and most frequently, researchers view work-life balance as the absence of work-family conflict, or the frequency and intensity in which work interferes with family or family interferes with work. Greenhaus and Allen (2006) defined work-life balance as "the extent to which an individual's effectiveness and satisfaction in work and family roles are compatible with the individual's life priorities" (Grzywacz and Carlson, 2007: 457). In other words, it refers as the extent to which an individual is able to adequately manage the multiple roles in their life, including work, family and other major responsibilities such as sports, community etc. (Haar, 2013: 4). Work-life balance experienced when demands from the work roles are compatible with demands from other domains like family, friends, health and spirit. Accordingly, a balanced living occurs when activities and aspirations in work domain do not have negative effects on activities in life. However, achieving a balanced life are generally related working time, flexibility, (un)employment, welfare, social security, family, fertility, migration, demographic changes, leisure time and gender. For instance both working men and women have work-life balance issues, but these issues play out often differs along gender. Men often act as though their job comes first, whereas women typically put family first. Moreover, men spend most of his time for career advancement and acquire more pay, while women spend most of her time with family and usually captured carrier barriers. In addition to these, it can be stated that work-life balance differentiate due to individual's family situation, household composition, breadwinner models, family size, and life plans (Pichler, 2009: 450-451; Ciric, 2013: 14). The last thirty years work-life balance is one of the core and central challenge for employees and organizations because of dramatic changes in workforce. Since the 1980s, work has changed through the deregulation of labor markets, globalization, and increasing competitive pressures on businesses. Based on these changes, organizations attempt to carry out some practices which have resulted in many employees working long hours, and an increased trend towards work intensification as to cut costs and to achieve great profit. In these conditions worklife balance emerge as a key factor highlighting the need to balance work and family in employment relations. Therefore, organizations need to understand implications of work-life balance and the ways or working practices which can benefit both employers and employees (Rose, Hunt and Ayers, 2007: 1; Burchielli and Thanacoody, 2008: 109). Because it is possible to generate that work-life balance positive and negative consequences both employers and employees. In literature, researchers have found relation between work-life balance and attitudinal job outcomes such as job satisfaction, organizational commitment, and organizational citizenship behavior, work-family conflict, turnover intention, absenteeism, employee performance, employee well-being, individual and organizational effectiveness (Grzywacz and Carlson, 2007: 456; Voydanoff, 2009: 161; Noor, 2011: 241). Concordantly, work-life balance seen as an important predictor of employees attitudes to their work roles and their general life so it becomes an important factor for organizations. Today's working environment requires organizations to design policies which can lead work-life balance and retain committed workforce.

\subsection{Life Satisfaction}

Life satisfaction generally is defined as having a favorable attitude towards one's life as a whole. From a broad perspective, life satisfaction represent as the product of a cognitive judgmental process that reflects the degree to which needs and life's expectations have been met, and is a comparison of aspirations with achievements in and judgments of life (Lindfors, et al., 2007: 817; Jan and Masood, 2008: 33). In this context, life satisfaction refers as an attitude or a summary evaluation of objects along a dimension ranging from positive emotions to negative. Accordingly, life satisfaction is an attitude which reflects our emotions and our assessments of life such as physical health, mental health, wealth, job, social relationships, and sense of accomplishment etc. These assessments or determinants of life satisfaction varies from person to person, because individuals evaluate of their life good or not can be change to the extent of some variables. In literature these variables classified as a social-demographic, individual and workplace factors. Social-demographic factors are characterized such as gender, race, ethnicity, age and education. Individual factors are personality, phys ical health, mental health, wealth, social relationships, sense of accomplishment, income etc. Workplace resource are categorized as a job characteristics, compensations, flexible work options, workplace retirement benefits, health insurance, working ours etc. (Pettay, 2008: 19; Jessica et al., 2008: 6). Life satisfaction evaluated as how one feels 
one's most important needs, goals, wishes are being met in important life domains, and this might lead to an excellent life which help us to engage activities in work and family life. However, life satisfaction or an excellent life can be expected to bring happiness and well-being to employees and ultimately increase their sense of accomplishment. (Sirgy, 2012: 15-17). In this regard, it is possible to express that life satisfaction is one of the major components of subjective well-being and some individual outputs such as positive affect and sense of accomplishment. (Vitters $\varnothing$, Biswas -Diener and Diener, 2005: 328). Moreover, the literature suggests that some variables as seen significant predictors of life satisfaction. For instance, personality, individual's recent life, work environment, family domain, income, social life, amount of discretionary time, working hours, positive and negative affect appear to be influential in determining life satisfaction (Eriksson, Rice and Goodin, 2006: 515; Jan and Masood, 2008: 33; Kapteyn, Smith and Van Soest, 2009: 16; Binder and Coad, 2010: 4). Based on the importance of life satisfaction one's overall quality of life, organizations must trying to understand which human resource policies can be ensured life satisfaction. Concordantly, it is critical to understanding of whether organizations should really invest in furthering work-life programs, and in enhancing employee's quality of life and life satisfaction. (Dolan and Gosselin, 2005: 3; Lapierre et al., 2008: 96).

\subsection{The Relationships among Family-Friendly Policies, Work-Life Balance, Work Alienation and Life Satisfaction}

Family-friendly policies have been used as an umbrella to define a wider range of organizational practices aimed to achieve a balance between work and family life's of employees in organizations. In other words, these practices are created a work environment which is family friendly and can help employees cope with work-family or work-life conflicts (Haslett, Smith and Curry, 2008: 21; Chou and Cheung, 2013: 4). However, implementation of family-friendly policies can help employees manage multiple work and nonworking responsibilities so that employees can balance their work and family life successfully. In literature, there is a plethora of evidence indicating that a family-friendly policies expected to provide work-life balance. Because these policies exemplify organizational efforts to support employee needs to balance work and family responsibilities. Therefore, employees' work-life balance is influenced by whether or not the company's family-supportive policies and procedures or work-family culture (i.e."the shared assumptions, beliefs, and values regarding the extent to which an organization supports and values the integration of employees' work and family lives). In this context, it is possible to assess that family-friendly policies as an organizational factors which play critical role on employees work-life balance (Allen, 2001: 415-416).

Establishing family-friendly policies is a critical step in creating a better "fit" between the workplace, job responsibilities and family commitments. Based on the goodness of fit between work and family life it is expected to affect work-related behaviors such as absenteeism, turnover intentions, tardiness, and organizational commitment, job satisfaction, job involvement, work alienation etc. At the same time, it is possible that these policies bring out favorable attitudes in the home domain such as life satisfaction (Daves, 2004: 8-13). As family-friendly policies facilitate employees to balance multiple roles in work and family life thus lead a higher quality of life, psychological involvement and life satisfaction (Haar, 2013: 3). Today, it is important that organizations to ensure a family-friendly work environment for their employees in order to help them better juggle work and family demands in ways that can benefit employees and organizations. In this context, ensuring such a work environment which include flexible working conditions, leave entitlements and other supportive policies such as health, insurance, care etc, will expect to provide positive output both employees and organizations. Moreover, perception of positive and supportive work environment may play a significant role in overall satisfaction employees in their life (Lapierre et al., 2008: 97-104). In literature, researches have been explored outcomes of family friendly policies such as job satisfaction, organizational commitment, turnover intention, absenteeism and work-life balance etc. Accordingly, in this study, it has been discussed outcomes of family-friendly policies. Within the scope of research, it has been taken worklife balance, and work alienation and life satisfaction which are expected an affect from these policies. Thus, this study aims to investigate the relationships among family-friendly policies, work-life balance, and work alienation and life satisfaction. In order to test these relationships, research model and hypothesis those shown below are developed. 


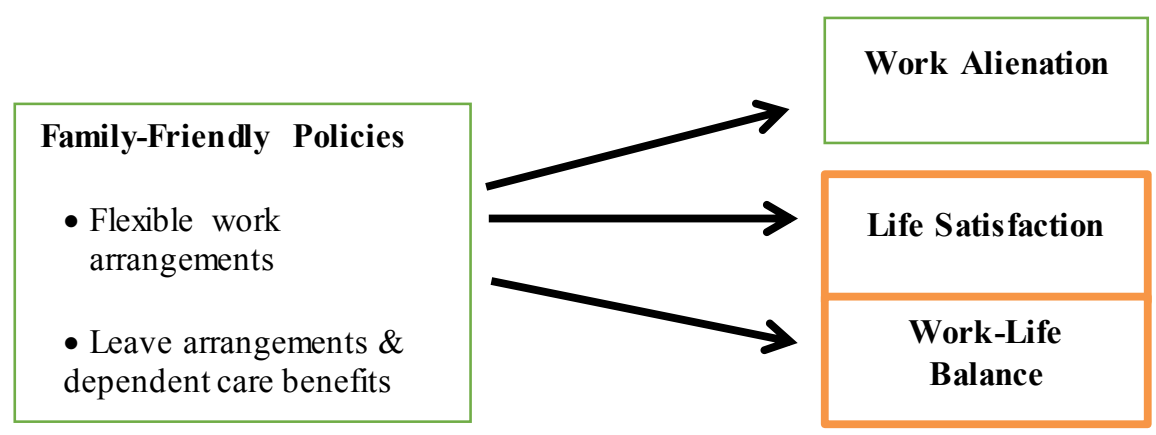

Fig.1 Research Model

H1: There is a statistically significant relationship between family-friendly policies and work alienation.

$\mathrm{H} 2$ : There is a statistically significant relationship between family-friendly policies and life satis faction.

H3: There is a statistically significant relationship between family-friendly policies and work-life balance.

\section{Research Methodology}

\subsection{Sample and Procedures}

This study is conducted in marble firms in Turkey. The sample used for the study consist of approximately 300 staff, who have been working in three different marble firms which are determined via convenient sampling method. From the 300 questionnaires that have been sent, 225 (\%75) have returned and $208(\% 69)$ have been accepted as valid and included in the evaluations. Questionnaire survey method is used for data collection. Questionnaire form contains four different measurement related to research variables.

\subsection{Meas urement}

Measures used in the questionnaire forms are adapted from the previous studies in literature. The variables used in the family-friendly policies measure; are taken from Allen (2001); Daves (2004); Brough, O'Driscoll and Kalliath (2005); Chou and Cheung (2013) studies. The variables work alienation measure is taken from Hirschfield, Feild and Bedeian (2000) study, work-life balance measure is taken from Waumsley, Houston and Marks (2010) study and life satisfaction measure is taken from Diener et al., (1985) study. For answers to the statements of survey, a Likert-type metric, that is, expressions with five intervals has been used. Anchored such; "1- strongly disagree, 2-disagree, 3- neither agree or nor disagree, 4- agree, 5-strongly agree". There are also ten demographic questions which is related (gender, age, marial status, income, number of children etc.) in the questionnaire. As a result of the conducted pilot study, it's been observed that the items in the factor analysis, where $(n=30)$ has been applied, displayed a proper distribution, in accordance with the theoretical characteristics.

\subsection{Statis tical Methods}

SPSS for Windows 20.0 program is used to analyze the data obtained by the questionnaire survey. Factor analysis is used to test the variables related to family-friendly policies, work alienation, work-life balance and life satisfaction. Besides, Cronbach Alpha values which determine the reliability levels of the scales that have been computed for each measure. In order to test the hypotheses the analyses of Pearson Correlation has been used and multiple regression analys is has been used also to explain the relationships among the family-friendly policies, work alienation, work-life balance and life satis faction. 


\section{Results}

\subsection{Demographical Findings}

$54 \%$ of employees, who have participated in the research, are female and $46 \%$ are male. $40 \%$ of the employees are between the ages $28-35,34 \%$ of them are between the ages of $36-43,3 \%$ of them are older than 43 and $23 \%$ of them younger than $28.72 \%$ of employees are married and $23 \%$ of them are single. $70 \%$ of employees have two or more child. $77 \%$ of employees have education of a primary school, $20 \%$ have graduated from high school (lycee). 3\% of employees have graduated vocational school and have bachelor's degree. Approximately 95\% of employees are working in production department (blue collar), 5\% of them are working in administrative departments (white collar). 18\% of employees have been working less than one year, 53\% of them have been working between 1-3 years, $21 \%$ of them have been working between $4-6$ years and $8 \%$ of the employees have been working more than 6 years in the this firm. However, $95 \%$ of employees are paid minimum wage.

\subsection{Factor and Reliability Analysis}

In the study, the structural validity and reliability levels of measures have been tested. First, data of the variables related to family-friendly policies have been put into factor analys is and the varimax rotation has been obtained. In the principal component analys is, the Kaiser-Meyer-Olkin test result (KMO value, $0.814)$ and the result of Bartlett test $(1609.163 ; \mathrm{p}<0.01)$ were significant. As a result of the varimax rotation of the data related to family-friendly policies variables, removing the items with factor loadings under 0.50 from the analys is, two factor solutions has been obtained. Emerged factors, explain $59.489 \%$ of the total variance. It can be seen that the remaining 13 items are grouped under the relevant factors as per theoretical structure. It can be said that the scale which are used can measure a single structure that complies with the theory and has structural validity. The findings on the resultant factors, factor loadings, explained variances, and internal consistency coefficients which are calculated for each factor (measure) are summarized in Table 1.

\section{Table 1. Rotated Factor Loadings with Calculated Family-Friendly Policies Measures}

\begin{tabular}{ll}
\hline Factor 1: Leave Arrangements \& Dependent Care Benefits (explained \\
variance = 31.147\%; Cronbach's Alpha = 0.86) \\
1. General support for family needs & \\
2. Easily use annual leave & 0.830 \\
3. Resources that help employees to be healthy and productive & 0.826 \\
4. Support systems such as leave plans to care for relatives & 0.764 \\
5. Health care insurance & 0.725 \\
6. Paid or unpaid time off for mother and father both when a child born & 0.711 \\
Factor 2: Flexible Working Arrangements (explained variance = 28.342\%; & 0.701 \\
Cronbach's Alpha $=\mathbf{0 . 8 3}$ ) (R) & \\
7. Long hours inside the office (R) & 0.840 \\
8. Compressed work week & 0.762 \\
9. Offering employees flexibility in completing their work & 0.751 \\
10. Job sharing program & 0.701 \\
11. Five-day work week & 0.664 \\
12. Flexible working time & 0.575 \\
13. The ideal employee is the one who is available 24 hours a day (R) & 0.572
\end{tabular}

The data of the variables related to work-life balance have been put into factor analysis and the varimax rotation has been obtained. In the principal component analysis, the Kaiser-Meyer-Olkin test result (KMO value, 0.647) and the result of Bartlett test $(639,609 ; \mathrm{p}<0.01)$ are significant. As a result of the varimax rotation of the data related to work-life balance variables, removing the items with factor loadings under 0.50 from the analysis, two factor solutions has been obtained. Emerged factors, explain 
$68.411 \%$ of the total variance. It can be seen that the remaining 7 items are grouped under the relevant factors as per theoretical structure. It can be said that the scales which are used can measure a single structure that complies with the theory and have structuralvalidity. The findings on the resultant factors, factor loadings, explained variances, and internal consistency coefficients which are calculated for each factor (measure) are summarized in Table 2.

Table 2. Rotated Factor Loadings with Calculated Work- Life Balance Measures

Factor 1: Life-Work Conflict (explained variance=41.608\%; Cronbach's Alpha=0.85)

1. Things I want to do at work don't get done because of the demands of my family

2. My home life interferes with my responsibilities at work

3. Family-related strain interferes with my ability to perform job-related duties

4. I have to put off doing things at work because of demands on my time at home

Factor 2: Work-Life Conflict (explained variance $=26.803 \%$; Cronbach's Alpha= 0.69)

5. My job produces strain that makes it difficult to fulfill family duties 0.903

6. Things I want to do at home do not get done because of the demands my job puts me 0.723

7. Due to work related duties, I have to make changes to my plans for family activities

The data of the variables related to work alienation have been put into factor analysis. In the principal component analysis, the Kaiser-Meyer-Olkin test result (KMO value, 0.736) and the result of Bartlett test $(736,686 ; p<0.01)$ are significant. As a result of the factor analysis, one factor solutions has been obtained. Emerged factor, explain $50.579 \%$ of the total variance. It can be seen that the remaining 6 items are grouped under the relevant factor as per theoretical structure. It can be said that the scale which is used can measure a single structure that complies with the theory and have structural validity. The findings on the resultant factor analys is, are summarized in Table 3.

Table 3. Factor Loadings with Calculated Work Alienation Measure

Factor 1: Work Alienation (explained variance= 50.579\%; Cronbach's Alpha=0.84)

1. It doesn't matter if people work hard at their jobs; only a few "higherups" really profit 0.809

2. I feel little need to try my best at work for it makes no difference anyway

3. I don't enjoy work; I just put in my time to get paid 0.798

4. Ordinary work is too boring to be worth doing

5. It is hard to believe people who actually feel that the work they perform is of value to society

6. I find it difficult to imagine enthusiasm concerning work

The data of the variables related to life satisfaction have been put into factor analysis. In the principal component analysis, the Kaiser-Meyer-Olkin test result (KMO value, 0.621) and the result of Bartlett test $(229,455 ; \mathrm{p}<0.01)$ are significant. As a result of the factor analysis, one factor solutions has been obtained. Emerged factor, explain $69.946 \%$ of the total variance. It can be seen that the remaining 3 items are grouped under the relevant factor as per theoretical structure. It can be said that the scale which is used can measure a single structure that complies with the theory and have structural validity. The findings on the resultant factor analysis are summarized in Table 4.

Table 4. Factor Loadings with Calculated Life Satisfaction Measures

Factor 1: Life Satisfaction (explained variance= 69.946\%; Cronbach's Alpha=0.78)

1. If I could live my life over, I would change almost nothing 0.907

2. So far I have gotten the important things I want in life (R) 0.887 


\subsection{Findings on the Research Hypotheses}

The findings obtained as a result of the correlation analysis performed on testing the existence of relationships denoted in the research hypothesis. According the findings in the research hypothesis denote the relationships among the variables which are summarized in Table 5.

Table 5. The Correlation among Family-Friendly Policies, Work-Life Balance, Work Alienation and Life Satisfaction

\begin{tabular}{llcccc}
\hline & 1 & 2 & 3 & 4 & Means \\
1. Family-Friendly Policies & & 1 & & & 2.50 \\
2. Work-Life Balance & $-.157^{*}$ & 1 & & & 3.09 \\
3. Work Alienation & $.357^{* *}$ & $-.433^{* *}$ & 1 & & 2.39 \\
4. Life Satisfaction & $-.317^{* *}$ & $.201^{* *}$ & $-.338^{* *}$ & 1 & 3.12 \\
& & & &
\end{tabular}

$* * \mathrm{p}<0.01, * \mathrm{p}<0.05$

In correlation analys is findings, a significant relationship $(r=357, p<0.01)$ is observed between the family-friendly policies and work alienation. There is a negative significant relationship $(\mathrm{r}=-317$, $\mathrm{p}<0.01$ ) between family-friendly policies and life satisfaction. There is a negative significant and poor relationship $(r=-157, p<0.01)$ between family-friendly policies and work-life balance. Accordingly, H1, $\mathrm{H} 2$ and $\mathrm{H} 3$ hypothesis are accepted. The findings obtained as a result of the correlation analysis performed on testing the existence of relationships denoted in the research hypothesis, and the findings obtained as a result of regression analysis performed for explanation of relationships among the dimensions of variables are summarized in Table 6,7 and 8 .

Table 6. Effects of Family-Friendly Policies on Work Alienation

\begin{tabular}{lcrrrr}
\hline & $\mathrm{R}^{2}$ & $\mathrm{~F}$ & & $\beta$ & $\mathrm{p}$ \\
& .171 & 21.198 & & & .000 \\
Flexible Working Arrangements & & & .357 & .000 & \\
Dependent Care Ben.\&Leave Arrangements & & .113 & & .101 \\
$* * \mathrm{p}<0.01, * \mathrm{p}<0.05$ & & &
\end{tabular}

Table 6 indicates the results of the regression analysis, which explain effects of the familyfriendly policies dimensions on work alienation. Model summary, Table 6 shows how much family friendly policies variables can explain work alienation. $17 \%$ work alienation of the variance are explained by one of the dimension of family-friendly policies. The regression model, explaining the impact of family-friendly policies on work alienation, is valid (with $\mathrm{F}=21.198 ; \mathrm{p}<0.01$ ). Positive beta values show that the increase in independent variables leads to an increase in work alienation, or a decrease in independent variables results in a decrease in work alienation. Accordingly; it is possible to express that flexible working arrangements which refers to dimension of family-friendly policies affect the work alienation positively. The other dimension which is characterized dependent care benefits and leave arrangements has no effect on work alienation. Thus, it can be said that if employees perceive inflexible working conditions in organizations, they can be disconnected from their works.

Table 7. Effects of Family-Friendly Policies on Life Satisfaction

$\begin{array}{lccccr} & \mathrm{R}^{2} & \mathrm{~F} & \beta & \mathrm{p} & \\ & .133 & 15.663 & & & \\ \text { Flexible Working Arrangements } & & & -.270 & .000 & \end{array}$


$* * \mathrm{p}<0.01, * \mathrm{p}<0.05$

Table 7 indicates the results of the regression analysis, which explain effects of the family friendly policies dimensions on life satisfaction. Model summary, Table 7 shows how much familyfriendly policies variables can explain life satisfaction. $13.3 \%$ life satisfaction of the variance are explained by two dimensions of family-friendly policies. The regression model, explaining the impact of family-friendly policies on life satisfaction, is valid (with $\mathrm{F}=15.663 ; \mathrm{p}<0.01$ ). Accordingly; it can be said that flexible working arrangements and dependent care benefits \&leave arrangements affect the life satisfaction negatively. In other words, if employees perceive inflexible working conditions in organizations, they can be dissatis fied with their lives. However, to the extent of beta values; it can be stated that life satisfaction is affected mostly the flexible working arrangements than dependent care benefits \& leave arrangements. Because it is possible to express that working hours, working conditions which allow employees flex working, job sharing or etc. are much more important than dependent care benefits \& leave arrangements upon the life satisfaction.

Table 8. Effects of Family-Friendly Policies on Work-Life Balance

\begin{tabular}{lcccc}
\hline & $\mathrm{R}^{2}$ & $\mathrm{~F}$ & $\beta$ & $\mathrm{p}$ \\
& .050 & 5.304 & & .006 \\
Flexible Working Arrangements & & & -.240 & .001 \\
Dependent Care Ben.\&Leave Arrangements & & .101 & .172 \\
\hline
\end{tabular}

$* * \mathrm{p}<0.01,{ }^{*} \mathrm{p}<0.05$

Table 8 indicates the results of the regression analysis, which explain effects of the familyfriendly policies dimensions on work-life balance. Model summary, Table 8 shows how much familyfriendly policies variables can explain work-life balance. $0.05 \%$ work-life balances of the variance are explained by one of the dimension of family-friendly policies. The regression model, explaining the impact of family-friendly policies on work-life balance, is valid (with $\mathrm{F}=5.304$; $\mathrm{p}<0.01$ ). Accordingly; it can be said that flexible working arrangements dimension of family-friendly policies affect the worklife balance negatively. In this context, these results reflect that employees perceive inflexible working conditions and due to this reason it is difficult to balance their work roles and family responsibilities. In other words, perceived negative conditions lead to decrease work-life balance.

\section{Conclusion}

Today's volatile and dynamic work conditions have brought about some changes in the labour market and work types. These changes, emerging in global working life and usually taken as the sociodemographic and technological advances, have a profound impact on individuals and organizations. In other words, the increase in competitive pressure and job insecurity, changes in the order of economy, the fact that money and status become an important value in the social life have caused individuals to work longer hours and integrated more and more women into the workforce. Thus, critical developments which have serious effect on individuals have also affected the lives and structures of family. In the $21^{\text {th }}$ century, there are individuals who have dual career, a flexible career, a specific career goal, work long hours at the same time, and those who are able to keep up with the intense working conditions. Therefore, it is possible to express that organizations have a great role for individuals to cope with these conditions, and to have a success ful work and family life. In current working conditions requires organization to support the work and family life of employees through culture, policies and procedures. In this context, for struggle to these conditions organizations need to develop and adopt policies which are characterized family-friendly policies according to the work and family lives of employees. Because family-friendly policies facilitate balancing the roles and responsibilities of individuals in their work and private life; thus, they enable the employees to have increased job and life 
satisfaction. In other words, the procedures which enable flexible working; let them have days -off in case of birth, child or elder care; support individuals in such matters as child care, social assistance, health insurance are expected to provide work-life balance; increase job satisfaction and reduce work alienation. In the literature, family -friendly policies are said to play a decisive role in the formation of such outcomes as work-life balance, job satisfaction, life satisfaction, and organizational commitment. Moreover, some researches indicate that family-friendly policies lead reduced work family conflict, turnover intention, work absenteeism, counterproductive behaviours and reduced productivity. In this context, family-friendly policies are seen as a precursor in providing positive outcomes as these policies are positive and for the welfare of employees. In other words, it is possible to express that familyfriendly policies are a precursor of positive attitudes such as work-life balance, organizational commitment, and job and life satisfaction. In a majority of the existing researches, family-friendly policies and work-life balance are studied. However, there are no studies in which work life balance, work alienation and life satisfaction are all discussed together. In this regard, this study aims to determine the impact of family-friendly policies on work-life balance, work alienation and life satisfaction. Hence, by exploring the impact of family-friendly policies in individual and organizational level and studying the impact of these policies on three different variables, this study is expected to contribute to the literature. As a result of the res earch significant correlations were found entire between all the variables based on the findings of the study conducted to determine the effect of family-friendly policies on work-life balance, work alienation and life satisfaction. Accordingly, there are sig nificant correlations between family-friendly policies and work-life balance, work alienation, and life satisfaction. In this context, $\mathrm{H} 1, \mathrm{H} 2$ and $\mathrm{H} 3$ hypothesis, developed within the framework of the research model, have been accepted. When the effect of family-friendly policies on work-life balance, work alienation and life satisfaction separately examined, it is seen that family-friendly policies have positive impact on the work alienation; it affects work-life balance negatively and in low levels, while life satis faction is negatively affected. However, if the scope of family-friendly policies are examined, some dimensions appears to be effective on work alienation, work- life balance and life satisfaction. For example, when the effect of family-friendly policies on work-life balance is examined, work-life balance is negatively affected by family-friendly policies dimension of flexible working conditions. In this context, it can be expressed that flexible working conditions have a reducing impact on work-life balance. At the same time work alienation is positively affected by family-friendly policies dimension of flexible working conditions. That is, perceived conditions in organizations increase work alienation of employees. Based on these findings, it is possible to state that family-friendly policies are negatively perceived in the organizations within the study scope; consequently, employees' work-life balance is negative affected and levels of alienation increase. When the effect of family-friendly policies on life satis faction, it is seen that the dimensions of "flexible working conditions" and "dependent care benefits \& leave arrangements" have negative effect on life satisfaction. According to these, it can be said that as the policies perceived by employees are negative in enterprises which are scope of the research and these policies lead to decrease of life satisfaction.

The research results indicate the presence of negative working conditions in marble enterpris es in which the research was carried out and also indicate that there are of human resources policies which do not support the family-friendly policies. Therefore, organizational conditions which do not support family and work lives of employees make it harder for individuals to establish a balance between their job roles and their responsibilities in their family lives; as a result, these conditions increase work alienation, while reducing life satisfaction of individuals. Therefore, enterprises need be aware of and give importance to family-friendly policies if they want to achieve top-level performance of their employees. Especially in the marble sector, such facts as heavy and intense working conditions; a good number of employees composed of women, married and married with children; the majority of employees receiving the minimum wage put emphas is on the importance of family-friendly policies much more. Because enterprises can make use of their employees only if they reduced the workload of employees; adjust working time according to the needs; allow necessary off-time in case of birth, illness, care of children and family members; provide supportive conditions such as child allowance, insurance, health care. In other words, thanks to these policies, employees are able to establish a balance between work and family life, and they feel work commitment and life satisfaction. 
Specific to enterprises involved in this study, the results differ from some studies in the literature. Available studies generally show that family-friendly policies affect work-life balance and life satisfaction positively, while they affect work alienation negatively. However, as family-friendly policies are evaluated negatively by the employees of the enterprises in which the research has been carried out so the results differ from some studies in the literature. In this context, work-life balance and life satis faction can be achieved through family-friendly policies; at the same time, work alienation can be reduced thanks to these policies. For future studies, the research model can be tested in sectors such as health and tourism; as a result, by researching the presence and effects of family-friendly policies in selected samples, it will be possible to contribute to the literature. Moreover, by adding variables such as the welfare of the employee, work- family conflict, the quality of work life, the research model can be expanded and the effect of family-friendly policies on these variables can be examined.

\section{References}

1. Ahmad, A. and Omar, Z.: Gender Differences in Work-Family Conflict and Family-Friendly Employment Policy Practices, The International Journal of The Humanities, Vol. 6, No. 3 (2008) 1526.

2. Allen, T. D.: Family-Supportive Work Environments: The Role of Organizational Perceptions, Journal of Vocational Behavior, Vol. 58 (2001) 414-435.

3. Amah, O. E.: Family-Work Conflict and the Availability of Work-Family Friendly Policy Relationship in Married Employees: The Moderating Role of Work Centrality and Career Consequence, Research and Practice in Human Resource Management, Vol. 18, No. 2 (2010) 35-46.

4. Bagilhole, B.: Family-Friendly Policies and Equal Opportunities: A Contradiction in Terms?, British Journal of Guidance \& Counselling, Vol. 34, No. 3 (2006) 327-343.

5. Banai, M., Reisel, W. D. and Probst, T. M. A.: Managerial and Personal Control Model: Predictions of Work Alienation and Organizational Commitment in Hungary, Journal of International Management, Vol. 10, No. 3 (2004) 375-392.

6. Baxter, J. and Chesters, J.: Perceptions of Work-Family Balance: How Effective Are Family-Friendly Policies?, Australian Journal of Labor Economics, Vol. 14, No. 2 (2011) 139-151.

7. Binder, M. and Coad, A.: Life Satisfaction and Self-Employment: A Matching Approach, The Papers On Economics and Evolution, Evolutionary Economics Group, MPI Jena, ISSN 1430-4716 (2010) $1-25$.

8. Breaugh, J., Frye, N.: Work-Family Conflict: The Importance of Family-Friendly Employment Practices and Family-Supportive Supervisors, Journal of Business \& Psychology, Vol. 22, No. 4 (2008) 345-353.

9. Brough, P., O’Driscoll, M. P. and Kalliath, T. J.: The Ability of Family Friendly Organizational Resources to Predict Work-Family Conflict and Job and Family Satisfaction, Stress and Health, Vol. 21 (2005) 223-234.

10. Burchielli, R., Bartram, T. and Thanacoody, R.: Work-Family Balance or Greedy Organizations?, Relations Industrielles/Industrial Relations, Vol. 63, No. 1 (2008) 108-133.

11. Callan, S.: Implications of Family-Friendly Policies For Organizational Culture: Findings From Two Case Studies, Work, Employment and Society, Vol. 21, No. 4 (2007) 673-691.

12. Carlson, D. S., Kacmar, K. M. and Williams, L. J.: Construction and Initial Validation of A Multidimensional Measure Of Work-Family Conflict, Journal Of Vocational Behavior Vol. 56, (2000) 249-276.

13. Chiaburu, D. S., Diaz, I. and De Vos, A.: Employee Alienation: Relationships with Careerism and Career Satis faction, Journal of Managerial Psychology, Vol. 28, No.1 (2013) 4-20.

14. Chou, K. L. and Cheung, K. C. K.: Family-Friendly Policies in the Workplace and their Effect on Work-Life Conflicts in Hong Kong, The International Journal of Human Resource Management, (2013), http://dx.doi.org/10.1080/09585192.2013.781529.

15. Ciric, N.: Family-Friendly Work Environment? An Investigation of Women's Job Stress and Satisfaction, Master Of Arts, University of Texas-Pan American. (2013)

16. Daves, J. L.: Family-Friendly/Work-Life Balance Policies: Employee Preferences, Supervisor and Organizational Support, and Retention Outcomes, Doctor Of Education, Peabody College Of Vanderbilt University. (2004). 
17. Diener, E., Emmons, R., Larsen, J., and Griffin, S.: The Satisfaction with Life Scale, Journal Of Personality Assessment, Vol. 49, No. 1 (1985) 71-75.

18. DiPietro, R.B. and Pizam, A.: Employee Alienation in the Quick Service Restaurant Industry, Journal of Hospitality \& Tourism Research, Vol. 32, No. 1 (2008) 22-39.

19. Dolan, S. and Gosselin, E.: Job Satisfaction and Life Satisfaction: Analysis of a Reciprocal Model with Social Demographic Moderators, Department of Economics and Business, Universitat Pompeu Fabra in its series Economics Working Papers with number 484 (2005) http://www.econ.upf.edu/docs/papers/downloads/484.pdf.

20. Drach-Zahavy, A. and Somec, A.: Coping with Work-Family Conflict: Integrating Individual and Organizational Perspectives, Korabik, K., Lero, D.S. and Whitehead, D.S. Handbook of WorkFamily Integration, Els evier Science \& Technology, UK (2008)

21. Eriksson, L., Rice, J. M. and Goodin, R. E.: Temporal Aspects of Life Satis faction, Social Indicators Research, 80 (2006) 511-533.

22. Grzywacz, J. G. and Carlson, D. S.: Conceptualizing Work-Family Balance: Implications for Practice and Research, Advances in Developing Human Resources, Vol. 9, No. 4 (2007) 455-471.

23. Haar, J. M.: Testing a New Measure of Work-Life Balance: A Study of Parent and Non-Parent Employees from New Zealand, The International Journal of Human Resource Management (2013) http://Dx.Doi.Org/10.1080/09585192.2013.775175.

24. Haslett, A., Smith, C. and Curry, V.: Family Friendly Work Practices at the University of Otago: It's Alright Here!, Otago Management Graduate Review, Vol. 6 (2008) 21-35.

25. Hirschfield, R. R. and Field, H. S.: Work Centrality and Work Alienation: Distinct Aspect of a General Commitment to Work, Journal of Organizational Behavior, Vol. 21, No. 7 (2000) 789-800.

26. Hirschfield, R. R., Field, H. S. and Bedeia, A. G.: Work Alienation as an Individual-Difference Construct for Predicting Workplace Adjustment: A Test in Two Samples, Journal of Applied Social Psychology, Vol. 30, No. 9 (2000) 1880-1902.

27. Jan, M. and Masood, T.: An Assessment of Life Satisfaction among Women, Stud. Home Comm. Sci., Vol. 2, No.1 (2008) 33-42.

28. Jessica, K. M., Johnson, M. P., Besen, E., Smyer, M. and Matz-Costa, C.: Quality of Employment and Life Satisfaction: A Relationship That Matters for Older Workers, The Center on Aging \&Work Workplace Flexibility, Boston College, Is sue Brief 13 (2008) 1-11.

29. Kapteyn, A., Smith, J. P. and van Soest, A.: Life Satisfaction, IZA Discussion Paper No. 4015 (2009) $1-42$.

30. Kim, J. and Wiggins, M.E.: Family-Friendly Human Resource Policy: Is It Still Working In the Public Sector?, Public Administration Review, September | October (2011) 728-739.

31. Lapierre, L. M., Spector, P.E., Allen, T. D., Poelmans, S., Cooper, C. L., O’Driscoll, M. P., Sanchez, J. I., Brough, P. and Kinnunen, U.: Family-Supportive Organization Perceptions, Multiple Dimensions of Work-Family Conflict, and Employee Satisfaction: A Test of Model across Five Samples, Journal of Vocational Behavior Vol. 73 (2008) 92-106.

32. Lee, S. Y. and Hong, J. H.: Does Family-Friendly Policy Matter? Testing Its Impact on Turnover and Performance, Public Administration Review, November | December (2011) 870-879.

33. Lindfors, P. M., Meretoja, O.A., Töyry, S. M., Luukkonen, R. A., Elovainio, M. J., Leino, T. J.: Job Satisfaction, Work Ability and Life Satisfaction among Finnish Anesthesiologists, Acta Anaesthesiol Scand, 51 (2007) 815-822.

34. Moon, S. Y. and Roh, J.: Balancing Work and Family in South Korea's Public Organizations: Focusing on Family-Friendly Policies in Elementary School Organizations, Public Personnel Management Vol. 39, No. 2 (2010) 117-131.

35. Mulvaney, M.: A Study of The Role of Family-Friendly Employee Benefits Programs, Job Attitudes, and Self-Efficacy among Public Park and Recreation Employees, Journal of Park and Recreation Administration, Vol. 29, No. 1 (2011) 58-79.

36. Nair, N. and Vohra, N.: An Exploration of Factors Predicting Work Alienation of Knowledge Workers, Management Decision, Vol. 48, No. 4 (2013) 600-615.

37. Nawab, S., Iqbal, S.: Impact of Work-Family Conflict on Job Satisfaction and Life Satisfaction, Journal of Basic and Applied Scientific Research, Vol. 3, No. 7 (2013) 101-110. 
38. Noor, K. M.: Work-Life Balance and Intention to Leave among Academics in Malaysian Public Higher Education Institutions, International Journal of Business and Social Science, Vol. 2, No. 11 (2011) 240-248.

39. Pettay, R. F.: Health Behaviors and Life Satisfaction in College Students, Doctor Of Philosophy, Kansas State University (2008).

40. Pichler, F.: Determinants of Work-Life Balance: Shortcomings in the Contemporary Measurement of WLB in Large-Scale Surveys, Soc Indic Res, Vol. 92 (2009) 449-469.

41. Poelmans, S. A. Y., Chinchilla, N. and Cardona, P.: The Adoption of Family-Friendly HRM Policies Competing for Scarce Resources in the Labor Market, International Journal of Manpower, Vol. 24, No. 2 (2003) 128-147.

42. Remery, C., Doorne-Huiskes, A. V. and Schippers, J.: Family-Friendly Policies in the Netherlands the Tripartite Involvement, Personnel Review, Vol. 32 No. 4 (2003) 456-473.

43. Rose, S., Hunt, T. and Ayers, B.: Adjust the Balance: Literature Review Life Cycles and Work Life Balance, Centre For Health Psychology, Staffordshire University, Http://Www.Equalworks.Co.Uk/Resources/contentfiles/4912.pdf (2007).

44. Schwartz, D. B.: An Examination of the Impact of Family-Friendly Policies on the Glass Ceiling, Cornell University ILR School, Federal Publications, http://digitalcommons.ilr.cornell.edu/key_workplace. (1994)

45. Sirgy, M. J.: The Psychology of Quality of Life, 2th Edition, Springer Science, U.S.A (2012)

46. Sulu, S., Ceylan, A. and Kaynak, R.: Work Alienation as a Mediator of the Relationship between Organizational Injustice and Organizational Commitment: Implications for Healthcare Professionals, International Journal of Business and Management, Vol. 5, No. 8 (2010) 27-38.

47. Tummers, L. and Dulk, L. D.: Meaningful Work for a Meaningful Life? Work Alienation and Its Effects in the Work and The Family Context, RSPM 2012.

48. Vitters $\varnothing$, J., Biswas-Diener, R. and Diener, E.D.: The Divergent Meanings of Life Satis faction: Item Response Modeling of the Satis faction with Life Scale in Green Land and Norway, Social Indicators Research, 74 (2005) 327-348.

49. Voydanoff, P.: A Conceptual Model of the Work-Family Interface, Korabik, K., Lero, D. S. and Whitehead, D. S. Handbook of Work-Family Integration, Elsevier Science \& Technology, UK (2008).

50. Vuksan, M., Williams, A. and Crooks, V.: Family Friendly Policies: Accommodating End-Of-Life Caregivers in Workplaces, International Journal of Workplace Health Management, Vol. 5 No. 1 (2012) 4-14.

51. Wang, P., Lawler, J. J. and Shi, K.: Implementing Family-Friendly Employment Practices in Banking Industry: Evidences from Some African and Asian Countries, Journal of Occupational and Organizational Psychology, Vol. 84 (2011) 493-517.

52. Wang, P. and Walumbwa, F. O.: Family-Friendly Programs, Organizational Commitment and Work Withdrawal: The Moderating Role of Transformational Leadership, Personnel Psychology, Vol. 60 (2007) 397-427.

53. Waumsley, J. A., Houston, D. M. and Marks, G.: What About Us? Measuring the Work-Life Balance of People Who Do Not Have Children, Review of European Studies, Vol. 2, No. 2 (2010) 3-17. 